\title{
Establishing Transcriptional Signatures to Differentiate PXR-, CAR-, and AhR-Mediated Regulation of Drug Metabolism and Transport Genes in Cryopreserved Human Hepatocytes
}

\author{
Jamie E. Moscovitz, Amit S. Kalgutkar, Kelly Nulick, Nathaniel Johnson, Zhiwu Lin, \\ Theunis C. Goosen, and Yan Weng \\ Medicine Design, Pfizer Inc., Cambridge, Massachusetts (J.E.M., A.S.K., Y.W.), and Medicine Design, Pfizer Inc., Groton, \\ Connecticut (K.N., N.J., Z.L., T.C.G.) \\ Received December 18, 2017; accepted February 8, 2018
}

\begin{abstract}
The potential for drug-drug interactions (DDIs) arising from transcriptional regulation of drug-disposition genes via activation of nuclear receptors (NRs), such as pregnane $X$ receptor (PXR), constitutive androstane receptor (CAR), and aryl hydrocarbon receptor $(\mathrm{AhR})$, remains largely unexplored, as highlighted in a recent guidance document from the European Medicines Agency. The goal of this research was to establish PXR-/CAR-/AhR-specific drug-metabolizing enzyme (DME) and transporter gene expression signatures in sandwich-cultured cryopreserved human hepatocytes using selective activators of PXR (rifampin), CAR (CITCO), and AhR (omeprazole). Dose response for ligand-induced changes to 38 major human DMEs and critical hepatobiliary transporters were assessed using a custom gene expression array card. We identified novel differentially expressed drug-disposition genes for PXR ( $\uparrow A B C B 1 / M D R 1, C Y P 2 C 9, C Y P 2 C 19$, and EPHX1, $\downarrow A B C B 11)$, CAR [ $\uparrow$ sulfotransferase (SULT) 1E1, uridine glucuronosyl
\end{abstract}

transferase (UGT) 2B4], and AhR ( $\uparrow$ SLC10A1/NTCP, SLCO1B1/OATP1B1], and coregulated genes (CYP1A1, CYP2B6, CYP2C8, CYP3A4, UGT1A1, UGT1A4). Subsequently, DME gene expression signatures were generated for known CYP3A4 inducers PF-06282999 and pazopanib. The former produced an induction signature almost identical to that of rifampin, suggesting activation of the PXR pathway, whereas the latter produced an expression signature distinct from those of PXR, CAR, or AhR, suggesting involvement of an alternate pathway(s). These results demonstrate that involvement of PXR/CAR/AhR can be identified via expression changes of signature DME/transporter genes. Inclusion of such signature genes could serve to simultaneously identify potential inducers and inhibitors, and the NRs involved in the transcriptional regulation, thus providing a more holistic and mechanism-based assessment of DDI risk for DMEs and transporters beyond conventional cytochrome P450 isoforms.

\section{Introduction}

Examination of the potential for clinical drug-drug interactions (DDIs) with investigational drugs is examined through in vitro inhibition of the catalytic activities of hepatic phase I and phase II drug-metabolizing enzymes (DMEs) [e.g., cytochrome P450 (P450) and uridine glucuronosyl transferases (UGTs)] (Williams et al., 2004; Wienkers and Heath, 2005; Chu et al., 2009; NDA022465, 2009) and hepatobiliary transporter-mediated uptake [e.g., organic anion-transporting polypeptide (solute carrier SLCO/OATP isoforms)] and efflux [e.g., multidrug resistant gene [ATP-binding

This work was supported by a Pfizer Worldwide Research and Development Postdoctoral Fellowship Award to J.E.M.

https://doi.org/10.1124/jpet.117.247296. cassette $(A B C B / \mathrm{MDR}) 1$ and breast cancer resistance protein $(A B C G 2 / \mathrm{BCRP})]$ (Giacomini et al., 2010). An additional source of DDIs can involve regulation of drug-disposition genes through activation of nuclear receptors (NRs), including pregnane X receptor (PXR), constitutive androstane receptor (CAR), and/or aryl hydrocarbon receptor (AhR) (Goodwin et al., 2002a; Willson and Kliewer, 2002; Xu et al., 2005). Quantitative assessment of DDI risk via NR activation uses primary human hepatocytes and focuses almost exclusively on the messenger RNA ( $m$ RNA) and catalytic activity increases in the major constitutively expressed human P450 isoform CYP3A4 (along with CYP2B6 and CYP1A1/2). Whereas prominent induction of CYP1A1/2 is a hallmark feature of AhR activation (Fahmi and Ripp, 2010), induction of human CYP3A4 or CYP2B6 can be coregulated by PXR and CAR (Lehmann et al., 1998; Goodwin et al., 1999, 2002a,b).

\footnotetext{
ABBREVIATIONS: ABC, ATP-binding cassette; AhR, aryl hydrocarbon receptor; ANOVA, analysis of variance; AUC, area under the plasma concentration time curve; BCRP, breast cancer resistance protein; CAR, constitutive androstane receptor; cDNA, complementary DNA; CES, carboxylesterase; CITCO, 6-(4-chlorophenyl)imidazo[2,1-b][1,3]thiazole-5-carbaldehyde 0 -(3,4-dichlorobenzyl)oxime; $C_{\text {max }}$, maximal plasma concentration; DDI, drug-drug interaction; DME, drug-metabolizing enzyme; DMSO, dimethylsulfoxide; $E_{\max }$, maximum effect; EPHX, epoxide hydrolase; GST, glutathione-S-transferase; HSD, hydroxysteroid dehydrogenase; MDR, multidrug resistant protein; MOI, maximal observed induction; mRNA, messenger RNA; MRP, multidrug resistance-associated protein; NR, nuclear receptor; OATP, organic anion-transporting polypeptide; OCT, organic cation transporter; PF-06282999, 2-(6-(5-chloro-2-methoxyphenyl)-4-oxo-2-thioxo-3,4-dihydropyrimidin-1(2H)-yl)acetamide; PPAR $\alpha$, peroxisome proliferator-activated receptor $\alpha$; PXR, pregnane X receptor; qPCR, quantitative polymerase chain reaction; SLC, solute carrier transporter; SULT, sulfotransferase; TKI, tyrosine kinase inhibitor; UGT, uridine glucuronosyl transferase.
} 
NR-mediated transcriptional regulation pathways are associated with characteristic and oftentimes overlapping target drug-disposition genes (Willson and Kliewer, 2002; Xu et al., 2005; Aleksunes and Klaassen, 2012; Wang et al., 2012); however, little is known regarding the potential of xenobiotics (including drugs) to regulate DMEs other than CYP1A2/2B6/3A4, a deficiency that is specifically noted in the European Medicines Agency (EMA) Guidelines on the investigation of drug interaction document (EMA, 2012). These deficiencies have also been highlighted by the Induction Working Group of the Innovation and Quality Consortium with regard to gaining a fundamental understanding of the mechanism(s) and implications of downregulation of drugdisposition genes (Hariparsad et al., 2017). A recent examination, which correlated physiochemical properties of $\sim 300$ compounds with respect to induction of P450 and transporter $m$ RNA in human hepatocytes, demonstrated that induction of CYP1A2/2B6/3A4 $m$ RNAs was observed with $16 \%-33 \%$ of the test compounds (Badolo et al., 2015). In contrast, transporter mRNAs [e.g., OATP1B1, organic cation transporter $S L C 22 A 1 / \mathrm{OCT} 1$, MDR1, multidrug resistance associated proteins $A B C C / \mathrm{MRP} 2$ and 3 and BCRP] were induced by $<10 \%$ of the tested compounds. Many of the active compounds, however, induced multiple DMEs and/or transporters (Badolo et al., 2015). Kandel et al. (2016) also assessed genome-wide changes to transcriptional pathways on the induction of PXR, CAR, and peroxisome proliferator-activated receptor $\alpha(\operatorname{PPAR} \alpha)$ after treatment of human hepatocytes with rifampin (PXR activator), 6-(4-chlorophenyl)imidazo[2,1-b][1,3]thiazole-5-carbaldehyde O-(3,4-dichlorobenzyl)oxime (CITCO, CAR activator), or WY14,643 (PPAR $\alpha$ activator). Although not specifically focused on DME and xenobiotic transport networks, this work confirmed several drug-disposition genes that were among the top 25 upregulated $m$ RNAs for each pathway, including CYP2B6/2C8/2C9/3A4 (PXR), CYP1A1/2/2B6/2C8/2C9/3A4 (CAR), and CYP2C8/3A4 (PPAR $\alpha$ ) (Kandel et al., 2016). These observations represent a pragmatic first step in the holistic analysis of genes subject to NR-mediated transcriptional regulation; however, the analysis is limited to the use of a single NR activator concentration in assessment of transcriptional regulation of major DMEs and transporters.

The present account summarizes our work on the categorization of multiple signature genes (Table 1) in human hepatocytes, which can mediate the metabolism or hepatobiliary disposition of xenobiotics and small-molecule drugs, as qualitative biomarkers for activation of PXR, CAR, or AhR by prototypic and selective activators rifampin, CITCO, and omeprazole, respectively (Fig. 1). Concentration-response relationships were explored to allow for the determination of $\mathrm{EC}_{50}$ and maximum effect $\left(\mathrm{E}_{\max }\right)$ values to aid in the interpretation of individual $m$ RNA induction data. The ability of genes to serve as qualitative biomarkers for specific PXR, CAR, or AhR activation was further tested with two structurally diverse compounds, namely, 2-(6-(5-chloro-2-methoxyphenyl)-4-oxo-2thioxo-3,4-dihydropyrimidin-1(2H)-yl)-acetamide (PF-06282999) and pazopanib (Fig. 1). PF-06282999 is a thiouracil-based irreversible inhibitor of the myeloperoxidase enzyme (Ruggeri et al., 2015; Dong et al., 2016), which induces CYP3A4 $m$ RNA and catalytic activity via PXR (but not CAR1 or CAR3) transactivation (Moscovitz et al., 2017) and causes statistically significant decreases in the systemic exposure of CYP3A4 substrate midazolam in healthy adult subjects (Dong et al., 2017). Pazopanib, an indazolylpyrimidine-based tyrosine kinase inhibitor (TKI), is a substrate (Keisner and Shah, 2011; Liu et al., 2016) and inhibitor (Hamberg et al., 2015) of CYP3A4. In vitro studies in human hepatocytes suggest pazopanib to be a moderate inducer of CYP3A4 and CYP2B6 $m$ RNA and catalytic activities, presumably via PXR activation (https://www.accessdata. fda.gov/drugsatfda_docs/nda/2009/022465s000_ClinPharmR.pdf).

\section{Materials and Methods}

Materials. PF-06282999 (chemical purity >99\% by highperformance liquid chromatography and nuclear magnetic resonance) was synthesized at Pfizer Worldwide Research and Development (Groton, CT). Hepatocyte thawing, plating, and incubation medium, as well as the Torpedo antibiotic mix for the medium, were purchased from Bioreclamation IVT Celsis (Baltimore, MD) and CellzDirect (Pittsboro, NC). Rifampin, CITCO, omeprazole, pazopanib, Dulbecco's phosphate-buffered saline, and dimethylsulfoxide (DMSO) were purchased from Sigma-Aldrich (St. Louis, MO). Cryopreserved human hepatocyte lots were purchased as follows: HH1089 (white woman, aged 57 years), In Vitro ADMET Laboratories (Columbia, MD); FOS (Arabic man, aged 34 years), and BNA (white man, aged 43 years) Bioreclamation IVT Celsis.

NR Transactivation Assays. Human PXR transactivation was determined by luciferase activity using a proprietary reporter cellbased assay according to the manufacturer's protocol (Indigo Biosciences, State College, PA). The assay uses reporter cells expressing a hybrid form of PXR containing native human PXR-ligand binding domain and the yeast GAL4-DNA binding domain, which regulates

TABLE 1

List of signature drug metabolizing enzyme and transporter genes included in panel

\begin{tabular}{lcccc}
\hline \multicolumn{1}{c}{ Phase I } & Phase II & Uptake Transporters & Efflux Transporters & NRs + Non-DME Targets \\
\hline AOX1 & GSTA1 & SLC10A1/NTCP & ABCB1/MDR1 & AhR \\
CES1 & GSTP1 & SLC22A1/OCT1 & ABCB4/MDR3 & NR0B2/SHP \\
CYP1A1 & SULT1E1 & SLC22A7/OAT2 & ABCB11/BSEP & NR1H4/FXR \\
CYP2B6 & UGT1A1 & SLC47A1/MATE1 & ABCC2/MRP2 & NR1I2/PXR \\
CYP2C8 & UGT1A4 & SLCO1B1/OATP1B1 & ABCC3/MRP3 & NR1I3/CAR \\
CYP2C9 & UGT1A6 & SLCO1B3/OATP1B3 & ABCC4/MRP4 & PDK4 \\
CYP2C19 & UGT1A9 & SLCO2B1/OATP2B1 & ABCC5/MRP5 & PPAR $\alpha$ \\
CYP2D6 & UGT2B4 & & ABCC6/MRP6 & \\
CYP3A4 & UGT2B7 & & ABCG2/BCRP & \\
EPHX1 & UGT2B15 & & & \\
EPHX2 & & & & \\
HSD11 $\beta 1$ & & & & \\
\hline
\end{tabular}

AOX, aldehyde oxidase; BSEP, bile salt export salt; CES1, carboxylesterase 1; FXR, farnesoid X receptor; OCT1 organic cation transporter 1; PDK4, pyruvate dehydrogenase kinase 4; SHP, small heterodimer partner (also known as NR0B2). 


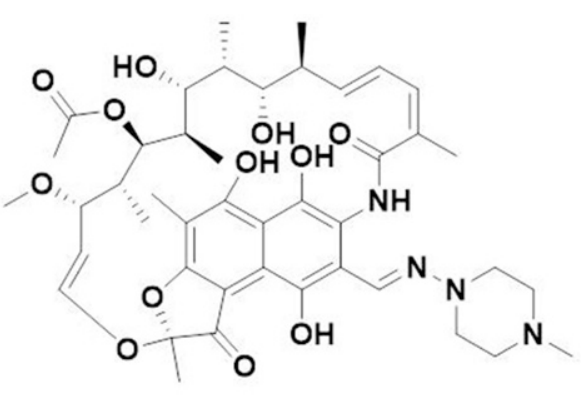

Rifampin<smiles>Clc1ccc(-c2nc3sccn3c2/C=N/OCc2ccc(Cl)c(Cl)c2)cc1</smiles>

CITCO<smiles>COC1=CC=C2NC([Se](=O)[O-])=NC(C[Se](=O)[O-])=C2C1</smiles>

Omeprazole<smiles>COc1ccc(Cl)cc1-c1cc(=O)[nH]c(=S)n1CC(N)=O</smiles>

PF-06282999<smiles>Cc1ccc(Nc2nccc(N(C)c3ccc4c(C)n(C)nc4c3)n2)cc1S(N)(=O)=O</smiles>

Pazopanib

Fig. 1. Chemical structures of the PXR agonists rifampin and PF-06282999, CAR agonist CITCO, AhR agonist omeprazole, and tyrosine kinase inhibitor pazopanib.

the expression of a luciferase reporter gene. Human CAR1 and CAR3 transactivation assays were conducted according to the manufacturer's recommendations (Puracyp, Inc., Carlsbad, CA). The assay consists of hepatoma cells transiently transfected with the full-length human CAR, splice variant 1 or 3 , and a luciferase reporter gene linked to the human promoters XRE and PXRE. Human AhR transactivation assays were conducted by Puracyp, Inc. This assay uses stably transfected proprietary reporter cells with the full-length human AhR and a luciferase reporter gene linked to the human CYP1A2 promoter dioxin response elements. For all transactivation assays, reporter cells were seeded into a 96 -well format assay plate and preincubated from 4 to 12 hours. Treatment followed with medium containing solvent (0.1\% DMSO) control, rifampin (0.03-30 $\mu \mathrm{M})$, CITCO $(0.005-20 \mu \mathrm{M})$, or omeprazole $(0.3-300 \mu \mathrm{M})$, after which medium was discarded and luciferase detection reagent was added to detect luciferase activity. The intensity of light emission from each assay well was quantified using a plate-reading luminometer.

Human Hepatocyte Culture and Treatment. Cryopreserved human hepatocytes (three donors per experiment) were used to examine $m$ RNA using established protocols (Fahmi et al., 2008b). The plates were overlaid with $0.25 \mathrm{mg} / \mathrm{ml}$ Matrigel 4 hours after plating, and the cultures were maintained in InVitroGro-HI medium. Hepatocytes were seeded in collagen I-precoated 48-well plates, and each well had a cell density of $\sim 1.6 \times 10^{5}$ viable cells. One day after plating, hepatocyte cultures were treated for 48 hours with medium containing solvent control (0.1\% DMSO), rifampin $(0.1-10 \mu \mathrm{M})$, CITCO $(0.001-1 \mu \mathrm{M})$, omeprazole $(0.03-3 \mu \mathrm{M}), \quad$ PF-06282999 (10-1000 $\mu \mathrm{M})$, or pazopanib $(0.1-10 \mu \mathrm{M})$ in triplicate. Final concentrations of rifampin, CITCO, and omeprazole were chosen based on selectivity of specific activators in NR transactivation assays.

RNA Isolation and Gene Expression Assays. Cryopreserved human hepatocytes were washed with phosphate-buffered saline, and total RNA was isolated using an RNeasy Kit (Qiagen, Valencia, CA) according to the manufacturer's recommendations. RNeasy lysis buffer (Buffer RLT) with $1 \% \beta$-mercaptoethanol was applied to plates and placed on a plate shaker for 10 minutes at $800 \mathrm{rpm}$. The concentration and purity of RNA were assessed using the Nanodrop 8000 spectrophotometer (Thermo Scientific, Wilmington, DE). Complementary DNA (cDNA) was generated using High-Capacity cDNA Synthesis (Applied Biosystems, Foster City, CA). mRNA expression was determined by quantitative polymerase chain reaction (qPCR) using a custom TaqMan array card containing 35 representative hepatic phase I and II DMEs [P450s, UGTs, sulfotransferases (SULTs), glutathione-S-transferases (GSTs), aldehyde oxidase, carboxylesterase (CES), epoxide hydrolase (EPHX)], hydroxysteroid dehydrogenase (HSD) $11 \beta 1$, and hepatobiliary transporters (SLC, SLCO, $\mathrm{ABC}$ ) (Table 1). In addition to hepatic DMEs and transporters, nondrug disposition genes, typically used as indicators for NR activation were also included as controls (NRs and Non-DME targets, Table 1). Approximately $50 \mathrm{ng}$ of cDNA per sample was loaded per port. Array cards were briefly centrifuged and sealed, and qPCR was performed with a ViiA7 Real-Time PCR machine (Life Technologies, Grand Island, NY). Gene expression was analyzed using Expression Suite (Life Technologies) software. The relative quantity of each target gene compared with an endogenous control gene (glyceraldehyde-3phosphate dehydrogenase) was calculated using the $\Delta \Delta$ CT method.

Data Analysis. Transactivation assay data from reporter cell lines are presented as mean \pm S.D. $m$ RNA expression data from cryopreserved human hepatocyte experiments are presented as mean \pm S.E. Statistical analysis was performed using GraphPad Prism v7 (La Jolla, CA). $m$ RNA expression data were plotted versus the concentration of rifampin, CITCO, omeprazole, PF-06282999, or pazopanib. Individual fitting was carried out on each hepatocyte donor using GraphPad Prism version 7 and was fit to either a four-parameter sigmoidal model (fitting $\mathrm{E}_{\max }$, Hill slope, and $\mathrm{EC}_{50}$, with baseline fixed at 1) or three-parameter sigmoidal model (fitting $\mathrm{E}_{\max }$ and $\mathrm{EC}_{50}$, with Hill slope and baseline each fixed at 1). The four-parameter model was preferred if adding the extra parameter produced a fit with $P<0.05$ compared with the three-parameter model by the built-in GraphPad extra sum-of-squares $F$ test. mRNA expression was analyzed by a two-way ANOVA followed by a Dunnett's multiple comparison test to compare overall mean differences between treatment groups. Significance was set at $P<0.05$. 


\section{Results}

PXR-, CAR-, and AhR-Specific Induction Signatures Based on Maximal Observed Induction. For each agonist, a minimum of five concentrations in the range of $0.1-10 \mu \mathrm{M}$ for rifampin, $0.01-1 \mu \mathrm{M}$ for CITCO, and $0.03-3$ $\mu \mathrm{M}$ for omeprazole were selected based on the specificity of each compound for its respective NR, as determined in the transactivation assays (Fig. 2). $m$ RNA expression was analyzed by qPCR with TaqMan array cards, normalized to vehicle control, and relative fold induction was plotted versus the concentration dose response for each agonist and donor hepatocyte lot. A maximal observed induction (MOI) was reported for each gene in each of the individual donor lots, and these data were averaged and visualized by heat maps (Fig. 3), with average relative fold induction/MOI indicated next to each gene name. After treatment of human hepatocytes (BNA, FOS, and HH1089 lots) with NR agonists, intervariability in fold induction of $m \mathrm{RNA}$ of several genes was observed among the individual lots, as noted in previous studies (Fahmi et al., 2008a,b). In general, BNA was the most sensitive to $m$ RNA induction by PXR, CAR, and AhR activators, followed by FOS and HH1089. Despite the variability in magnitude, the patterns of target gene induction, the relative sensitivity of target genes (compared among each other for a particular donor lot), and the minimal day-to-day experimental variation remained consistent.

Activation of PXR, CAR, and AhR by selective activators rifampin, CITCO, and omeprazole, respectively, resulted in differing gene expression profiles and magnitude of induction for target genes (Fig. 3A). Rifampin, CITCO, and omeprazole treatment led to selective induction of CYP3A4, CYP2B6, and CYP1A1 mRNA by 75-fold, 22-fold, and 37-fold, respectively, in the three human-hepatocyte donor lots. In addition, rifampin treatment induced CYP2B6 and CYP2C $8>10$-fold, as well as UGT1A4, UGT1A1, CYP2C19, and CYP2C9 between 3 - and 5 -fold. Likewise, CAR activation by CITCO induced phase I and II DMEs and transporters, albeit in a less robust fashion than rifampin, including CYP3A4, CYP2C8, UGT1A1, SULT1E1, and UGT1A4 between 2- and 5-fold. Subsequent to CYP1A1, omeprazole most prominently induced CYP2B6 (14-fold $\uparrow$ ) and UGT1A1, SLC10A1, SLCO1B1, and CYP3A4 (2- to 3-fold $\uparrow$ ). qPCR quantification of $m$ RNA expression was also able to detect the downregulation of genes included in the panel, which was a considerably less frequent event than upregulation. Rifampin treatment resulted in significant downregulation of ABCB11 (Fig. 3). No significant downregulation of DMEs or transporters included in the panel was observed with CITCO or omeprazole activation of CAR and AhR, respectively.

Lot-to-lot variability of cryopreserved human hepatocytes has been described in the literature via ranges of CYP3A4 $\mathrm{EC}_{50}$ and $\mathrm{E}_{\max }$ values (Fahmi et al., 2008a,b), as well as principal component analysis (Kandel et al., 2016) of multiple donors. As such, this variability was considered in our assessment of true signature genes, and only those that were robustly reproducible across donors were included as a final signature gene in response to a PXR, CAR, or AhR activator (Fig. 4). Criteria as a signature gene (upregulation or downregulation) for an NR included statistically significant induction ( $\geq 2$-fold) relative to vehicle control, as determined by two-way ANOVA followed by a Dunnett's multiple comparison test in two or more donors and at one or more concentrations. PXR-specific target genes included ABCB1, CYP2C9, CYP2C19, and EPHX1. CAR-specific target genes included SULT1E1 and UGT2B4, whereas AhR alone significantly induced SLC10A1 and SLCO1B1. PXR and CAR coregulated CYP2B6, CYP2C8, and UGT1A4, whereas CYP1A1, CYP3A4, and UGT1A1 were upregulated upon activation of all three NRs.

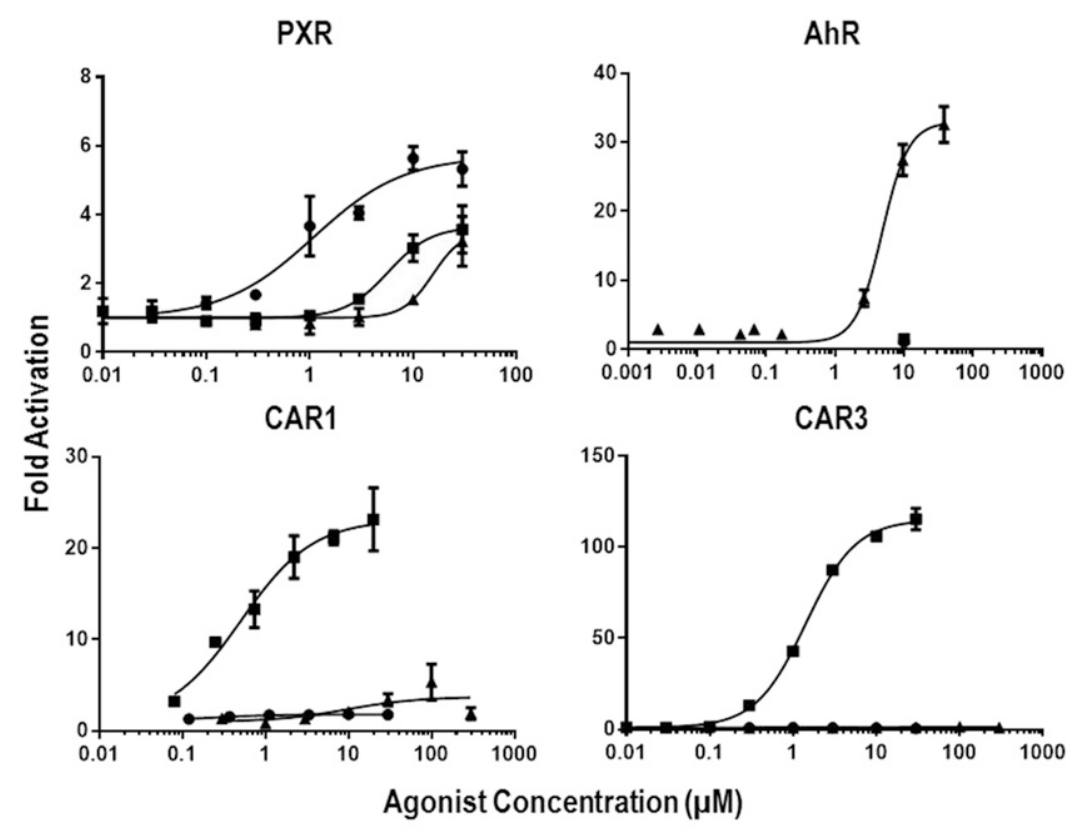

Fig. 2. Selection of activator concentration range with PXR, CAR, and AhR transactivation in luciferase-based reporter assay. Reporter cells were treated with solvent (0.1\% DMSO) control, rifampin $(0.03-30 \mu \mathrm{M})$, CITCO $(0.005-20 \mu \mathrm{M})$, or omeprazole $(0.3-300 \mu \mathrm{M})$, after which the drug-containing medium was removed and replaced with medium containing luciferase detection reagent, and luminescence was measured on a luminometer. All sigmoidal dose-response data were fit by nonlinear regression. 
A

\begin{tabular}{|c|c|c|c|c|c|c|c|c|}
\hline \multicolumn{3}{|c|}{ Rifampin PXR Agonist } & \multicolumn{3}{|c|}{ CITCO CAR Agonist } & \multicolumn{3}{|c|}{ OmeprazoleAhR Agonist } \\
\hline Gene & & MOI & Gene & & MOI & Gene & & MOI \\
\hline $\begin{array}{l}\text { CYP3A4 } \\
\text { CYP2B6 }\end{array}$ & $\begin{array}{l}74.50 \\
1929\end{array}$ & & CYP2B6 & 21.51 & & CYP1A1 & 36.90 & \\
\hline CYP2C8 & 12.41 & & CYP3A4 & 4.03 & & & & \\
\hline UGT1A4 & 7.87 & & & & & CYP2B6 & 2.41 & \\
\hline UGT1A1 & 4.61 & & CYP2C8 & 3.61 & & & & \\
\hline CYP2C19 & 3.72 & & UGTIAI & 2.84 & & UGT1A1 & 2.20 & \\
\hline $\begin{array}{r}\text { GSTA1 } \\
\text { SLCO1B1 }\end{array}$ & 3.19 & & & & & & & \\
\hline $\begin{array}{r}\text { SLCO1B1 } \\
\text { CYP2C9 }\end{array}$ & 3.14 & & SULT1E1 & 2.09 & & SLC10A1 & 2.13 & \\
\hline $\begin{array}{r}\text { CYP2C9 } \\
\text { SLCO2B1 }\end{array}$ & 3.09 & & $S C O 181$ & 208 & & & & \\
\hline $\begin{array}{r}S L C O 2 B 1 \\
A B C B 1\end{array}$ & 2.86 & & Jetrotiot & & & SLCO1B1 & 2.10 & \\
\hline $\begin{array}{l}\text { ABCB1 } \\
\text { GSTP1 }\end{array}$ & 2.50 & & UGT1A4 & 2.05 & & & & \\
\hline $\begin{array}{r}\text { GSTP1 } \\
\text { UGT2B4 }\end{array}$ & 2.45 & & EPHX1 & 178 & & CYP3A4 & 2.00 & \\
\hline 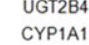 & 2.43 & & & & & & & \\
\hline $\begin{array}{l}\text { EPHX1 } \\
\text { SHX }\end{array}$ & 2.12 & & GSTA1 & 1.73 & & UGT1A4 & 1.82 & \\
\hline CES1 & 2.04 & & UGT2B4 & 171 & & & & \\
\hline CYP2D6 & 1.97 & & & & & GSTP1 & 1.77 & \\
\hline SLC22A1 & 1.91 & & CYP1A1 & 1.71 & & CYP3C8 & & \\
\hline UGT1AG & 1.90 & & CYP2C19 & 1.62 & & cirzeo & 1.14 & \\
\hline SLC10A1 & 1.76 & & & & & & & \\
\hline $\mathrm{ABCB4}$ & 1.68 & & GSTP1 & 1.57 & & SLCO2B1 & 1.73 & \\
\hline ABCC6 & 1.59 & & & & & & & \\
\hline AOX1 & 1.54 & & CYPZC9 & 1.54 & & CYP2C19 & 1.59 & \\
\hline UGT2B7 & 1.53 & & $\mathrm{ABCG} 2$ & 153 & & & & \\
\hline AHR & 1.52 & & & & & UGT2B 4 & 1.57 & \\
\hline ABCG2 & 1.51 & & NR112 & 0.91 & & & & \\
\hline $\mathrm{ABCC5}$ & 1.51 & & & & & GSTA1 & 1.56 & \\
\hline UGT2B15 & 0.95 & & NR0B2 & 0.90 & & & & \\
\hline NROB2 & 0.90 & & ABCB11 & 0.88 & & ABCB4 & 1.51 & \\
\hline EPHX2 & 0.87 & & & & & & & \\
\hline $\mathrm{NR} 1 \mathrm{H} 4$ & 0.81 & & NR113 & 0.88 & & ABCB11 & 150 & \\
\hline HSD11B1 & 0.80 & & & & & & & \\
\hline SULT1E1 & 0.75 & & PDK4 & 0.88 & & NR112 & 090 & \\
\hline SLC22A7 & 0.70 & & SLC22A7 & 0.87 & & & & \\
\hline $\begin{array}{l}\text { NR113 } \\
\text { PDK4 }\end{array}$ & 0.69 & & $\mathrm{NR} 1 \mathrm{H} 4$ & 078 & & HSD11B1 & 0.88 & \\
\hline$A B C B 11$ & 0.57 & & & & & & & \\
\hline SLCO1B3 & 0.47 & & SLC22A1 & 0.70 & & SLC47A1 & 0.78 & \\
\hline
\end{tabular}

B

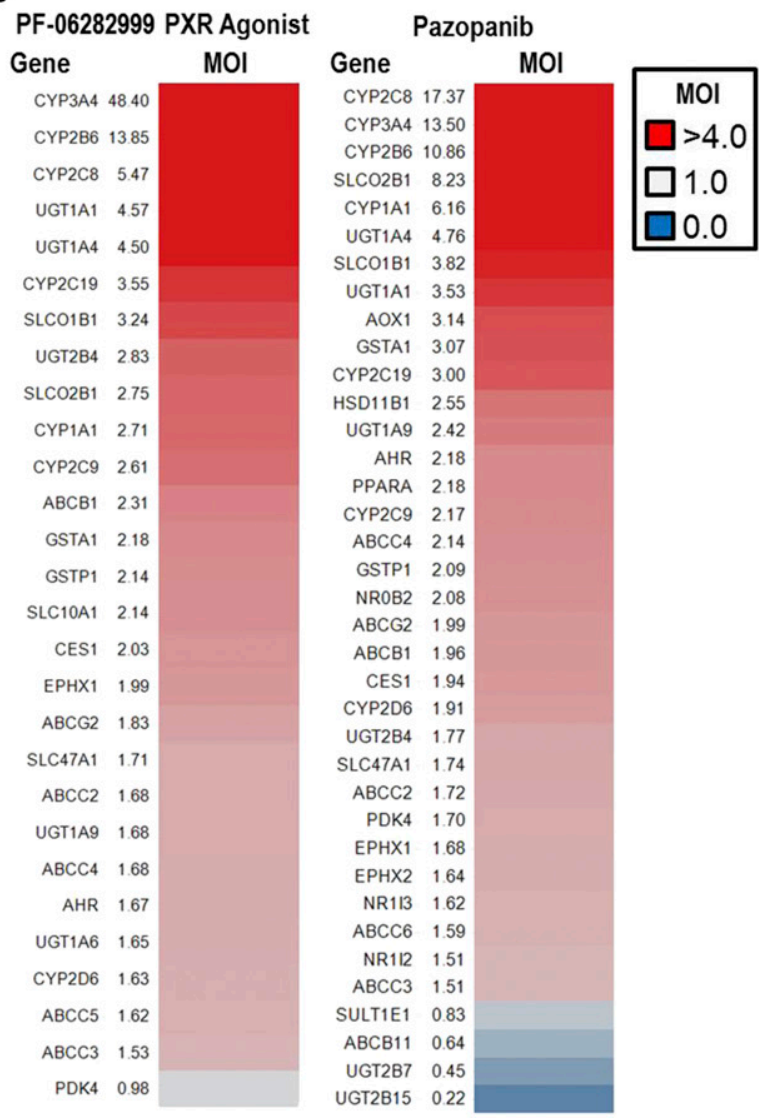

Fig. 3. MOI signatures with PXR, CAR, and AhR activation. $m$ RNA expression was analyzed by qPCR with TaqMan array cards and was plotted versus the concentration dose response for selective activators rifampin $(0.1-10 \mu \mathrm{M})$, CITCO $(0.01-1 \mu \mathrm{M})$, omeprazole $(0.03-3 \mu \mathrm{M})$ (A), and test compounds PF-06282999 (10-1000 $\mu \mathrm{M})$ or pazopanib $(0.1-10 \mu \mathrm{M})(\mathrm{B})$. Data are expressed as MOI at a single concentration normalized to $0.1 \%$ DMSO control. MOI was determined for each donor $(n=3)$ and averaged for a representative singular MOI per gene per treatment.

Under the current experimental conditions, the gene induction profile PF-06282999 most closely matched that of rifampin, although at lower magnitudes, given its weak PXR agonist activity (Fig. 3B). Thus, treatment of primary hepatocytes with PF-06282999 on average induced CYP3A4 48-fold, followed by CYP2B6 (14-fold) and CYP2C8 (5.5-fold), as well as UGT1A1, UGT1A4, and CYP2C19 between 3- and 5 -fold. As expected, PF-06282999 induced the same genes as

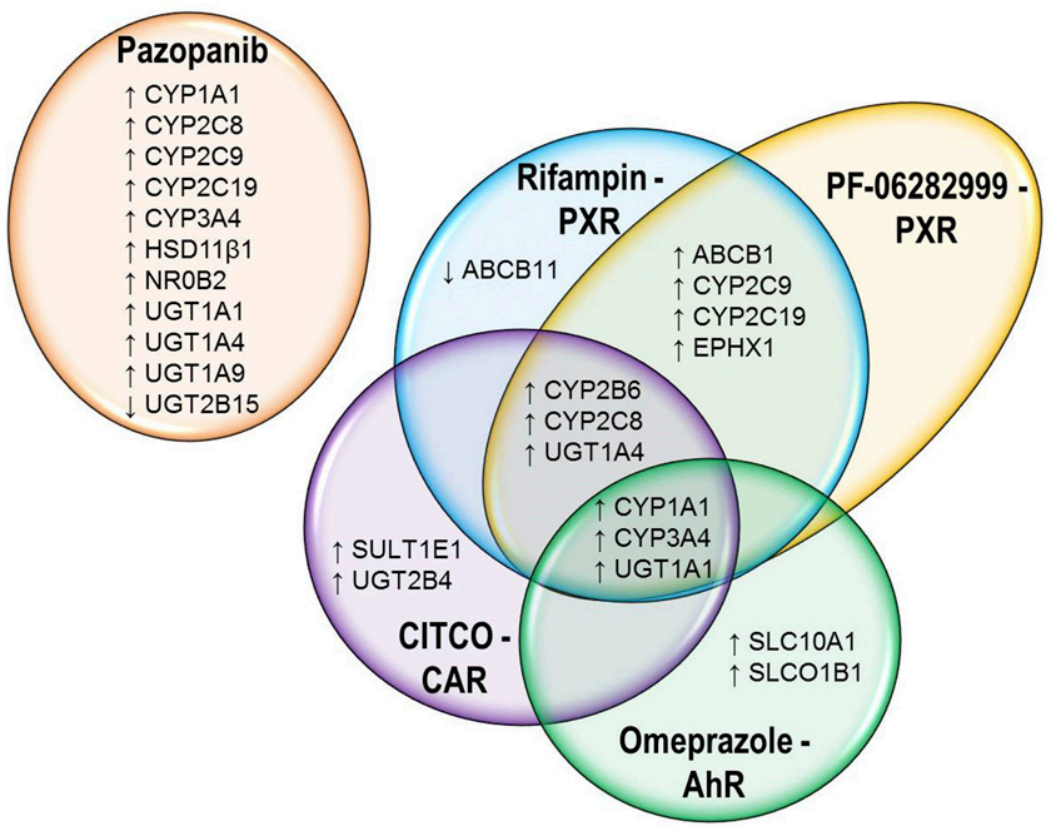

Fig. 4. Illustration of differentiating and overlapping gene expression signatures for PXR, CAR, and AhR. MOI of $m$ RNA expression was analyzed by a two-way ANOVA, followed by a Dunnett's multiple comparison test, to compare overall mean differences between treatment groups. Significance was set at $P<0.05$. Categories were determined by the following criteria: 1) fold change in $m \mathrm{RNA}$ expression $\geq 2$-fold compared with respective $0.1 \%$ DMSO control; 2) fold change observed in two or more donors at one or more concentrations. 


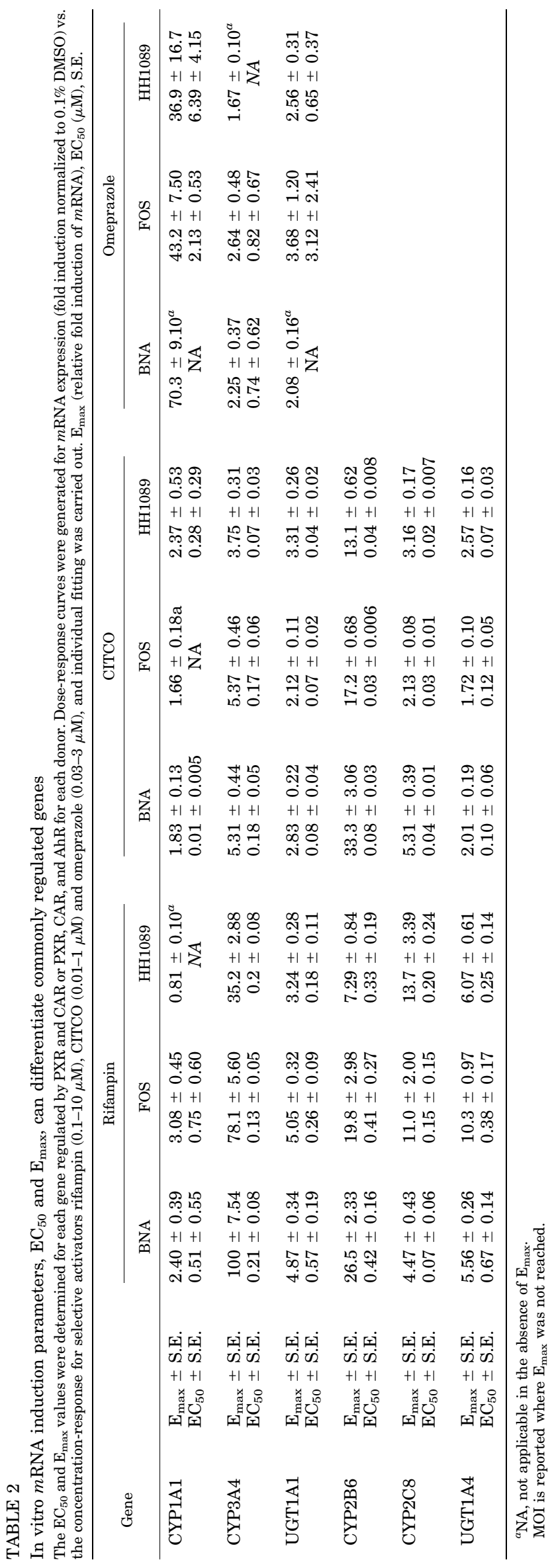

rifampin (Fig. 4), suggesting activation of the same gene regulation pathway and consistent with our previous study (Moscovitz et al., 2017). A significant downregulation of ABCB11 was not detected with PF-06282999, likely because of its weaker PXR activation. In contrast, the TKI pazopanib demonstrated a distinct gene expression signature by enhancing CYP2C8 by 17 fold, followed by CYP3A4 and CYP2B6 >10-fold, and CYP1A1 by 6 -fold (Fig. 3B). Unlike the selective NR activators, pazopanib also induced the gene expression of HSD11 $\beta 1$, UGT1A9, and NR0B2 (>20-fold). Marked downregulation of UGT2B15 (78\%) was observed with pazopanib treatment. Thus, pazopanib enhanced genes commonly regulated by PXR, CAR, and AhR (CYP1A1, CYP3A4, UGT1A1), PXR, and CAR (CYP2C8, UGT1A4), PXR (CYP2C9, CYP2C19), but also distinct genes such as HSD11 $\beta 1$, NR0B2, UGT1A9, with profound downregulation of UGT2B15 (Fig. 4).

Minimal DME and Transporter Gene List to Enable Differentiation between PXR and CAR. Further analyses of the full dose response curves (where possible) for genes that were inducible via PXR and CAR or PXR, CAR, and AhR were performed to assess whether it could provide further differentiation. For these genes, concentration response curves were generated for $m$ RNA expression (fold induction normalized to $0.1 \%$ DMSO) versus the concentrations for rifampin, CITCO, and omeprazole, and individual fitting was carried out on each hepatocyte donor using a three-parameter or four-parameter sigmoidal model. The in vitro parameters $\mathrm{EC}_{50}$ and $\mathrm{E}_{\max }$ were calculated for each donor concentration response curve (Table 2). Where $\mathrm{E}_{\max }$ could not be reached (BNA, omeprazole for CYP1A1 and UGT1A1; FOS, CITCO for CYP1A1; HH1089, rifampin for CYP1A1, omeprazole for CYP3A4), MOI is reported in the table.

CYP1A1, CYP3A4, and UGT1A1 were commonly regulated by PXR, CAR, and AhR, whereas PXR and CAR both induced CYP2B6, CYP2C8, and UGT1A4. Across all three donors, and in line with the MOI data, rifampin activation of PXR resulted in the highest $\mathrm{E}_{\max }$ of CYP3A4 (35- to 100-fold) and lowest $\mathrm{EC}_{50}$ (0.13-0.21 $\mu \mathrm{M})$. Similarly, CITCO treatment of cryopreserved human hepatocytes produced a higher CYP2B6 $\mathrm{E}_{\max }$ with a lower $\mathrm{EC}_{50}$, 13- to 33-fold and 0.03-0.08 $\mu \mathrm{M}$, respectively, than rifampin treatment. Although the $\mathrm{EC}_{50}$ for omeprazole induction of CYP1A1 ranged from 2 to $6 \mu \mathrm{M}$ across donors, the $\mathrm{E}_{\max }$ (37- to 43-fold) was significantly higher than that of rifampin and CITCO treatment, which resulted in $\mathrm{E}_{\max }$ values of between 2- and 3-fold. For UGT1A1, the $\mathrm{E}_{\max }$ was higher for rifampin; however, CITCO $\mathrm{EC}_{50}$ values were lowest but resulted in $m \mathrm{RNA}$ induction of only 2- to 3-fold. To apply the use of both $\mathrm{EC}_{50}$ and $\mathrm{E}_{\max }$ values for mRNA expression versus the concentration response curves, genes that were commonly regulated by both PXR and CAR were plotted for rifampin-, CITCO-, and PF-06282999-treated cells for all three primary human hepatocyte donor lots (Fig. 5). For rifampin and PF-06282999, responsiveness of target genes across hepatocyte lots was as follows: CYP3A4 > CYP2B6 > CYP2C8 > UGT1A1 = UGT1A4 $=\mathrm{CYP} 1 \mathrm{~A} 1$. With CITCO treatment, the responsiveness of target genes differed: CYP2B6 > CYP3A4 = CYP2C8 = UGT1A1 > UGT1A4 > CYP1A1.

\section{Discussion}

Consistent with the literature, our present study demonstrated that treatment of human hepatocytes with rifampin, 
CITCO, and omeprazole resulted in MOI of CYP3A4, CYP2B6, and CYP1A1 $m$ RNA (Gonzalez et al., 1984; Sutter et al., 1994; Bertilsson et al., 1998; Lehmann et al., 1998; Maglich et al., 2002, 2003; Badolo et al., 2015). Rifampin-mediated PXR activation in human hepatocytes also resulted in the greatest number of differentially regulated genes, including ABCB1, CYP2C9, and CYP2C19, which was generally consistent with prior results (Gerbal-Chaloin et al., 2001; Synold et al., 2001; Raucy et al., 2002; Jigorel et al., 2006; Yajima et al., 2014). The differential induction of EPHX1 $m$ RNA by rifampin in our study is consistent with the previous observations on the induction of this detoxification enzyme in mice after subchronic treatment with the rodent Pxr activator pregnenolone 16 $\alpha$-carbonitrile (Xie et al., 2000; Cui and Klaassen, 2016). Human liver microsomal EPHX1 hydrolyzes protein- and/or DNA-reactive epoxides (Seidegard and Ekstrom, 1997) that are obtained via P450-mediated oxidations on aromatic/ heteroaromatic rings and/or olefinic substituents in drugs such as phenytoin and carbamazepine (Fretland and Omiecinski, 2000). Whether increased EPHX1 $m$ RNA via PXR activation in human hepatocytes leads to a higher rate of detoxification of electrophilic epoxides generated via CYP3A/ 2C-mediated xenobiotic bioactivation remains to be assessed. $\mathrm{ABCB} 11 \mathrm{mRNA}$ repression with rifampin was the only robust downregulation noted in hepatocyte donors with prototypical inducer treatment and has been observed in a previous study (Jigorel et al., 2006); however, conflicting reports have also been published in human liver slices demonstrating no change (Marschall et al., 2005) or upregulation (Olinga et al., 2008) of ABCB11 $m$ RNA.

Upregulation of SULT1E1 mRNA by the CAR activator CITCO in human hepatocytes is consistent with previous data indicating gender-specific Sult1e1 activation in female mouse liver in response to Car ligands diallyl sulfide (Sueyoshi et al., 2011) or 1,4-bis[2-(3,5-dichloropyridyloxy)]benzene (Baskin-Bey et al., 2006; Alnouti and Klaassen, 2008). Upregulation of SULT1E1 $m$ RNA by CITCO in both female (HH1089) and male (BNA) human hepatocyte lots implies that gender-specific upregulation of SULT1E1 via CAR activation may be restricted to rodents specifically. Increases in $m$ RNA of UGT2B4 noted with CITCO in our study have not been observed previously in animals or human reagents. Assessment of UGT2B4 regulation in human hepatocytes in regard to bile acid metabolism identified NRs (farnesoid $\mathrm{X}$ receptor and $\mathrm{PPAR} \alpha$ ) commonly involved in endogenous cholesterol pathways (Barbier et al., 2003a,b). AhR activation by omeprazole was uniquely associated with increases in $m$ RNA for SLC10A1, which is consistent with the work of Olinga et al. (2008), who identified SLC10A1 upregulation in human liver slices
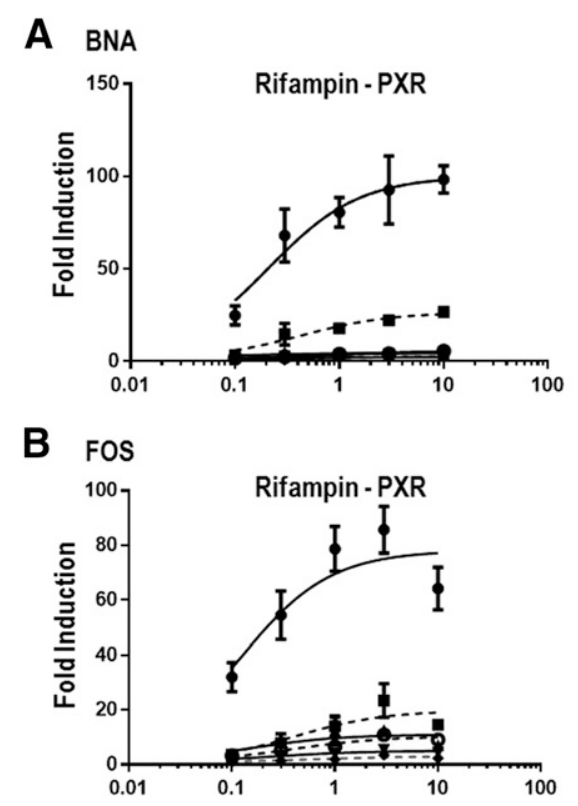

C $\mathrm{HH}_{1089}$

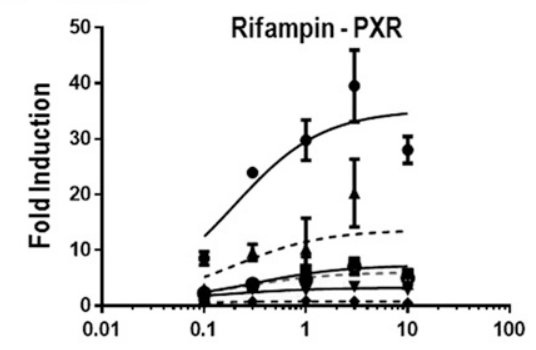

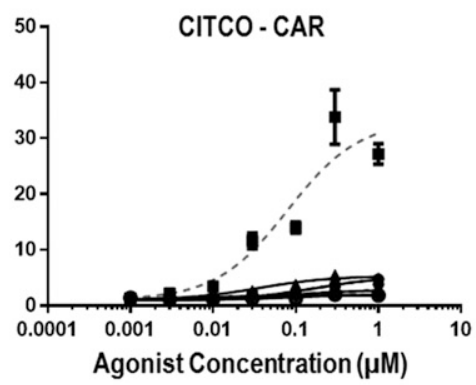
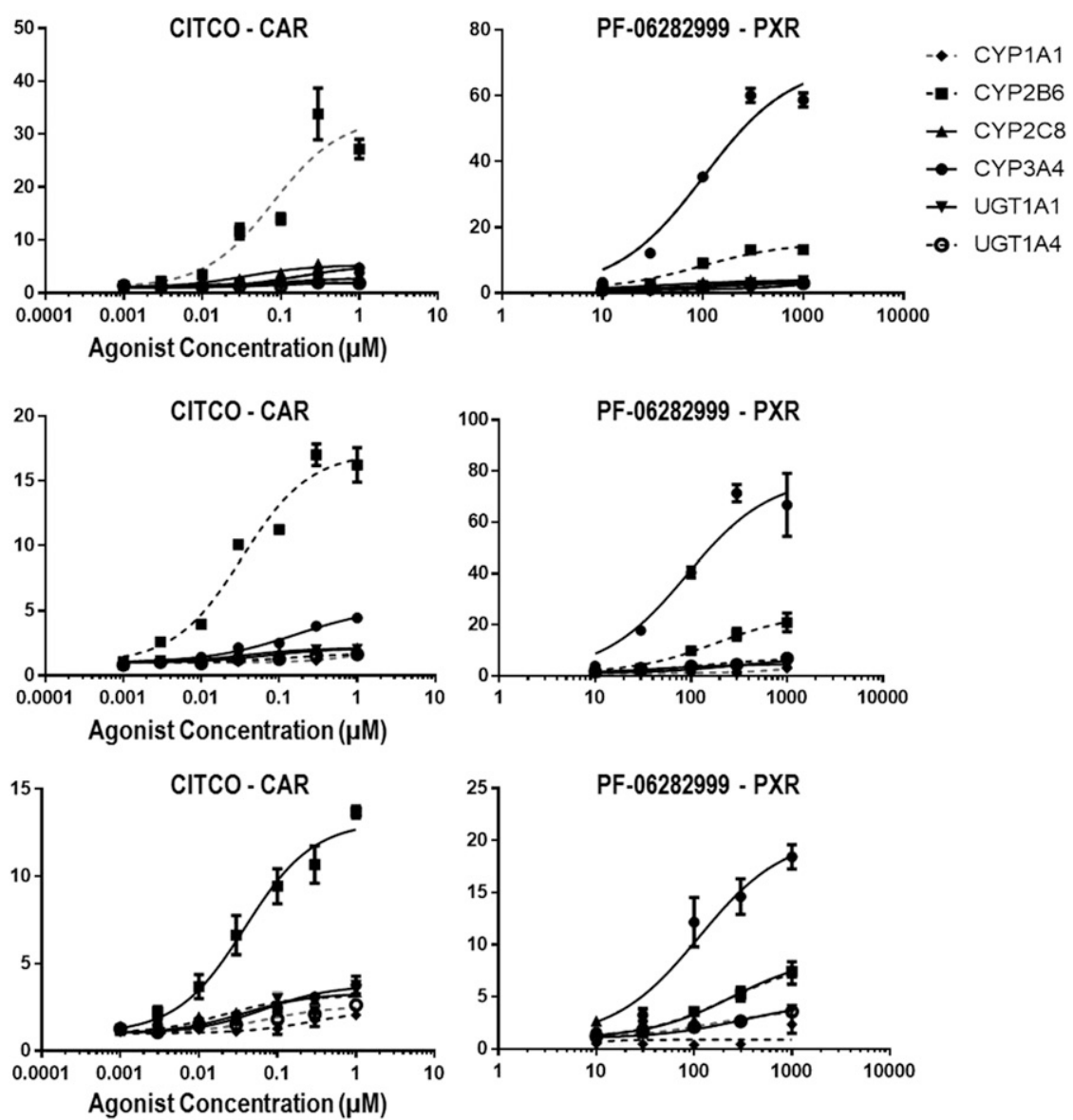

Fig. 5. In vitro $m$ RNA induction dose-response curves for differentiating PXR and CAR agonists. $m$ RNA expression was analyzed by $q P C R$ with TaqMan array cards and was plotted versus the concentration dose response for rifampin $(0.1-10 \mu \mathrm{M})$, CITCO $(0.01-1 \mu \mathrm{M})$, or PF-06282999 (10-1000 $\mu \mathrm{M}$ ) for donors BNA (A), FOS (B), and HH1089 (C). Individual fitting was carried out on each hepatocyte donor (A-C) and was fit to either a fourparameter sigmoidal model or a three-parameter sigmoidal model. 
treated with the AhR agonist $\beta$-napthoflavone (Olinga et al., 2008). The upregulation of SLCO1B1 by omeprazole, also noted in our work, appears to be a novel finding.

Previous reports using $m$ RNA and protein assessment in primary human hepatocytes, HepG2 cells, and reporter assays revealed that CYP2B6, CYP3A4, and UGT1A1 gene expression was coregulated by PXR and CAR (Honkakoski et al., 1998; Goodwin et al., 2001; Sugatani et al., 2005; Sinz et al., 2006; Sinz, 2015). In addition, the induction of UGT1A1 gene expression in human hepatoma HepG2 cells has been noted with AhR activation (Yueh et al., 2003). Studies have also identified the response elements in UGT1A1 corresponding to each NR (Sugatani et al., 2001; Xie et al., 2003; Yueh et al., 2003), as well as PXR response elements in CYP3A4, CYP2B6, and UGT1A1 in primary human hepatocytes (Hariparsad et al., 2009). The six DME targets (CYP1A1/2B6/2C8/3A4, UGT1A1/1A4) that were induced (albeit at varying magnitudes) by PXR and CAR or PXR, CAR, and AhR in our work are responsible for the metabolism of $>70 \%$ of marketed drugs (Williams et al., 2004; Guengerich, 2008). Activator concentration response relationships $\left(\mathrm{E}_{\max }\right.$ and $\mathrm{EC}_{50}$ ) for $m \mathrm{RNA}$ expression were determined, which provided relevance with respect to the concentrations needed to elicit, and the maximal effect possible for activation of each gene by PXR, CAR, and AhR. For example, rifampin-treated human hepatocytes resulted in a dramatic lot dependent $\mathrm{E}_{\max }$ of 35- to 100-fold and $\mathrm{EC}_{50}$ of $0.13-0.21 \mu \mathrm{M}$ for CYP3A4 $m \mathrm{RNA}$ expression. Although the $\mathrm{EC}_{50}$ for CYP3A4 $m$ RNA increase with CITCO treatment was comparable to that of rifampin $(0.07-0.18 \mu \mathrm{M})$, the $\mathrm{E}_{\max }$ ranged from only 3.8- to 5.4-fold. This approach highlights the importance of assessing $\mathrm{EC}_{50}$ in conjunction with $\mathrm{E}_{\max }$ for an accurate depiction of $\mathrm{NR}$ target gene sensitivity and possibly for quantitative prediction of DDIs.

The myeloperoxidase inactivator PF-06282999 performed identically to rifampin, inducing a comparable gene expression profile, albeit to a lesser extent (consistent with its weak PXR agonist activity). The profile consisted of genes identified as PXR-specific; PXR- and CAR-overlapping; and PXR, CAR, and AhR overlapping. Importantly, the genes suggesting CAR or AhR activation alone were not induced by PF-06282999. This compound also differentiated itself from the selective CAR agonist CITCO in its concentration response curves for overlapping PXR and CAR target genes. In these analyses, the relative rank-ordered sensitivity of ADME genes was identical for rifampin and PF-06282999, but not CITCO, in all three donor lots.

Clinical DDIs arising from induction of major P450 enzymes by NR activators are plentiful (Pelkonen et al., 2008); however, DDIs arising from upregulation of non-P450 enzymes are scarce with drugs (or drug candidates). Wenning et al. (2009) demonstrated a $\sim 40 \%$ reduction in plasma area under the curve (AUC) and $\mathrm{C}_{\max }$ of the selective UGT1A1 substrate raltegravir in humans pretreated with rifampin (600 mg daily for 14 days) (Wenning et al., 2009). In comparison, the same dose of rifampin (dosed daily for 5 days) reduces the AUC and $\mathrm{C}_{\max }$ of the CYP3A4 probe substrate midazolam by $96 \%$ and $94 \%$, respectively (Backman et al., 1996). The clinical interaction between rifampin and selective substrates of UGT1A1 and/or CYP3A4 supports our in vitro observations in which human hepatocytes treated with rifampin $(10 \mu \mathrm{M})$ for 48 hours resulted in the induction of both CYP3A4 and UGT1A1 $m$ RNA by 35 - to 100 - and 3- to 5-fold, respectively. The in vivo DDI study with raltegravir also confirms previous literature (Marschall et al., 2005; Sugatani et al., 2005; Hariparsad et al., 2009) that has revealed increased UGT1A1 $m$ RNA and enzyme activity in response to PXR activators. Cumulatively, the combined data also suggest that maximal DDIs with a PXR activator will occur at the level of CYP3A4 followed by enzymes activated at lesser magnitudes. Contextualizing the in vitro $\mathrm{EC}_{50}$ and $\mathrm{E}_{\max }$ values for rifampin-induced UGT1A1 $m$ RNA and enzyme activity in relation to its human unbound plasma concentrations can shed additional light on the DDI with raltegravir.

Finally, pazopanib was included in this analysis because of a previous report suggestive of CYP3A4 induction in vitro (https://www.accessdata.fda.gov/drugsatfda_docs/nda/2009/ 022465s000_ClinPharmR.pdf) (NDA-022465, 2009). To our surprise, treatment of human hepatocytes with pazopanib resulted in a profile distinct from PXR, CAR, or AhR activators. Pazopanib induced P450 (CYP2C8/2C9/2C19/ 3A4) and UGT (UGT1A1/1A4/1A9) isoforms while significantly downregulating UGT2B15. Non-DME target genes such as HSD11 $\beta 1$ and NR0B2, typical target genes of alternate NR pathways, were also susceptible toward induction by pazopanib. These data suggest that CYP3A4 induction by pazopanib is not mediated through PXR activation. Consistent with this hypothesis, recent transactivation data from our laboratory have revealed that pazopanib is not a PXR activator (unpublished observations). Studies are under way to identify the transcriptional regulator(s) for pazopanib and structurally diverse TKIs. Downregulation of UGT2B15 $m$ RNA will require correlation with corresponding decreases in UGT2B15 catalytic activity in relation to potential DDIs with drugs metabolized by UGT2B15. It is important to note that the package insert for pazopanib does not highlight DDIs arising from CYP3A4 induction as a liability. Rather, reports on clinical DDIs arising from inhibition of CYP3A4 (Keisner and Shah, 2011) and CYP2C 8 by pazopanib have appeared in the literature (Tan et al., 2010; Hamberg et al., 2015) and reflect a dominance of CYP3A4 inhibition over CYP3A4 induction as a causative factor for a DDI.

Current mathematical models (Fahmi et al., 2008a,b) used to project the magnitude of clinical DDIs arising from in vitro induction of CYP3A4 $m$ RNA and catalytic activity for selective PXR activators can be potentially extended to include other phase I (e.g., P450) and phase II (e.g., UGT) enzymes (Hariparsad et al., 2017); however, this method may not be applicable for compounds that induce CYP3A4 through selective CAR activation or via an unknown pathway/mechanism (e.g., pazopanib). This would also hold true for downregulation events, for which there is no known correlation with the magnitude of CYP3A4 upregulation. Therefore, identifying the mechanism by which compounds upregulate or downregulate DMEs and transporters will be a crucial prerequisite for predicting DDIs. Studies are currently under way to determine changes in UGT1A1/2B15 activities that could potentially accompany upregulation and downregulation of UGT mRNA by rifampin and pazopanib, respectively, in human hepatocytes.

In conclusion, this is the first detailed report that enables a holistic and mechanism-based assessment of DDI risk as a result of transcriptional regulation of DME and transporter genes beyond the conventional P450 (CYP3A4/2B6/1A2) enzymes and represents the first step toward addressing the 
concerns outlined by the regulatory agencies. Our present method can be conveniently adapted to the current standard practice used in the pharmaceutical industry since the protocol used in our studies was an established work flow involving the use of human hepatocytes to characterize P450 enzyme inducers.

\section{Acknowledgments}

We thank Dr. Larry Tremaine and Dr. Dennis Scott for critical discussions and feedback pertaining to this work.

\section{Authorship Contributions}

Participated in research design: Weng, Kalgutkar, Moscovitz, Goosen.

Conducted experiments: Moscovitz, Johnson.

Contributed new reagents or analytic tools: Nulick, Lin.

Performed data analysis: Moscovitz, Johnson, Weng, Kalgutkar.

Wrote or contributed to the writing of the manuscript: Moscovitz, Kalgutkar, Weng.

\section{References}

Aleksunes LM and Klaassen CD (2012) Coordinated regulation of hepatic phase I and II drug-metabolizing genes and transporters using AhR-, CAR-, PXR-, PPAR $\alpha$-, and Nrf2-null mice. Drug Metab Dispos 40:1366-1379.

Alnouti Y and Klaassen CD (2008) Regulation of sulfotransferase enzymes by prototypical microsomal enzyme inducers in mice. $J$ Pharmacol Exp Ther 324: $612-621$.

Backman JT, Olkkola KT, and Neuvonen PJ (1996) Rifampin drastically reduces plasma concentrations and effects of oral midazolam. Clin Pharmacol Ther 59: $7-13$.

Badolo L, Jensen B, Säll C, Norinder U, Kallunki P, and Montanari D (2015) Evaluation of 309 molecules as inducers of CYP3A4, CYP2B6, CYP1A2, OATP1B1, OCT1, MDR1, MRP2, MRP3 and BCRP in cryopreserved human hepatocytes in sandwich culture. Xenobiotica 45:177-187.

Barbier O, Duran-Sandoval D, Pineda-Torra I, Kosykh V, Fruchart JC, and Staels B (2003a) Peroxisome proliferator-activated receptor alpha induces hepatic expression of the human bile acid glucuronidating UDP-glucuronosyltransferase 2B4 enzyme. J Biol Chem 278:32852-32860.

Barbier O, Torra IP, Sirvent A, Claudel T, Blanquart C, Duran-Sandoval D, Kuipers F, Kosykh V, Fruchart JC, and Staels B (2003b) FXR induces the UGT2B4 enzyme in hepatocytes: a potential mechanism of negative feedback control of FXR activity. Gastroenterology 124:1926-1940.

Baskin-Bey ES, Huang W, Ishimura N, Isomoto H, Bronk SF, Braley K, Craig RW, Moore DD, and Gores GJ (2006) Constitutive androstane receptor (CAR) ligand, TCPOBOP, attenuates Fas-induced murine liver injury by altering Bcl-2 proteins. Hepatology 44:252-262.

Bertilsson G, Heidrich J, Svensson K, Asman M, Jendeberg L, Sydow-Bäckman M, Ohlsson R, Postlind H, Blomquist P, and Berkenstam A (1998) Identification of a human nuclear receptor defines a new signaling pathway for CYP3A induction. Proc Natl Acad Sci USA 95:12208-12213.

Chu V, Einolf HJ, Evers R, Kumar G, Moore D, Ripp S, Silva J, Sinha V, Sinz M, and Skerjanec A (2009) In vitro and in vivo induction of cytochrome p450: a survey of the current practices and recommendations: a pharmaceutical research and manufacturers of america perspective. Drug Metab Dispos 37:1339-1354.

Cui JY and Klaassen CD (2016) RNA-Seq reveals common and unique PXR- and CAR-target gene signatures in the mouse liver transcriptome. Biochim Biophys Acta 1859:1198-1217.

Dong JQ, Gosset JR, Fahmi OA, Lin Z, Chabot JR, Terra SG, Le V, Chidsey K, Nouri P, Kim A, et al. (2017) Examination of the human cytochrome P4503A4 induction potential of PF-06282999, an irreversible myeloperoxidase inactivator: integration of preclinical, in silico, and biomarker methodologies in the prediction of the clinical outcome. Drug Metab Dispos 45:501-511.

Dong JQ, Varma MV, Wolford A, Ryder T, Di L, Feng B, Terra SG, Sagawa K, and Kalgutkar AS (2016) Pharmacokinetics and disposition of the thiouracil derivative PF-06282999, an orally bioavailable, irreversible inactivator of myeloperoxidase enzyme, across animals and humans. Drug Metab Dispos 44:209-219.

European Medicines Agency (EMA) (2012) Guideline on the Investigation of Drug Interactions, Committee for Human Medicinal Products. London.

Fahmi OA, Boldt S, Kish M, Obach RS, and Tremaine LM (2008a) Prediction of drugdrug interactions from in vitro induction data: application of the relative induction score approach using cryopreserved human hepatocytes. Drug Metab Dispos 36 1971-1974.

Fahmi OA, Maurer TS, Kish M, Cardenas E, Boldt S, and Nettleton D (2008b) A combined model for predicting CYP3A4 clinical net drug-drug interaction based on CYP3A4 inhibition, inactivation, and induction determined in vitro. Drug Metab Dispos 36:1698-1708.

Fahmi OA and Ripp SL (2010) Evaluation of models for predicting drug-drug interactions due to induction. Expert Opin Drug Metab Toxicol 6:1399-1416.

Fretland AJ and Omiecinski CJ (2000) Epoxide hydrolases: biochemistry and molecular biology. Chem Biol Interact 129:41-59.

Gerbal-Chaloin S, Pascussi JM, Pichard-Garcia L, Daujat M, Waechter F, Fabre JM, Carrère N, and Maurel P (2001) Induction of CYP2C genes in human hepatocytes in primary culture. Drug Metab Dispos 29:242-251.
Giacomini KM, Huang SM, Tweedie DJ, Benet LZ, Brouwer KL, Chu X, Dahlin A, Evers R, Fischer V, Hillgren KM, et al.; International Transporter Consortium (2010) Membrane transporters in drug development. Nat Rev Drug Discov 9:215-236.

Gonzalez FJ, Tukey RH, and Nebert DW (1984) Structural gene products of the Ah locus. Transcriptional regulation of cytochrome P1-450 and P3-450 mRNA levels by 3-methylcholanthrene. Mol Pharmacol 26:117-121.

Goodwin B, Hodgson E, D'Costa DJ, Robertson GR, and Liddle C (2002a) Transcriptional regulation of the human CYP3A4 gene by the constitutive androstane receptor. Mol Pharmacol 62:359-365.

Goodwin B, Hodgson E, and Liddle C (1999) The orphan human pregnane X receptor mediates the transcriptional activation of CYP3A4 by rifampicin through a distal enhancer module. Mol Pharmacol 56:1329-1339.

Goodwin B, Moore LB, Stoltz CM, McKee DD, and Kliewer SA (2001) Regulation of the human CYP2B6 gene by the nuclear pregnane X receptor. Mol Pharmacol 60:427-431. Goodwin B, Redinbo MR, and Kliewer SA (2002b) Regulation of cyp3a gene transcription by the pregnane x receptor. Annu Rev Pharmacol Toxicol 42:1-23.

Guengerich FP (2008) Cytochrome p450 and chemical toxicology. Chem Res Toxicol 21: 70-83.

Hamberg P, Mathijssen RH, de Bruijn P, Leonowens C, van der Biessen D, Eskens FA, Sleijfer S, Verweij J, and de Jonge MJ (2015) Impact of pazopanib on docetaxel exposure: results of a phase I combination study with two different docetaxel schedules. Cancer Chemother Pharmacol 75:365-371.

Hariparsad N, Chu X, Yabut J, Labhart P, Hartley DP, Dai X, and Evers R (2009) Identification of pregnane-X receptor target genes and coactivator and corepressor binding to promoter elements in human hepatocytes. Nucleic Acids Res 37:1160-1173. Hariparsad N, Ramsden D, Palamanda J, Dekeyser JG, Fahmi OA, Kenny JR, Einolf H, Mohutsky M, Pardon M, Siu YA, et al. (2017) Considerations from the IQ induction working group in response to drug-drug interaction guidance from regulatory agencies: focus on downregulation, CYP2C induction, and CYP2B6 positive control. Drug Metab Dispos 45:1049-1059.

Honkakoski P, Zelko I, Sueyoshi T, and Negishi M (1998) The nuclear orphan receptor CAR-retinoid $\mathrm{X}$ receptor heterodimer activates the phenobarbitalresponsive enhancer module of the CYP2B gene. Mol Cell Biol 18:5652-5658.

Jigorel E, Le Vee M, Boursier-Neyret C, Parmentier Y, and Fardel O (2006) Differential regulation of sinusoidal and canalicular hepatic drug transporter expression by xenobiotics activating drug-sensing receptors in primary human hepatocytes. Drug Metab Dispos 34:1756-1763.

Kandel BA, Thomas M, Winter S, Damm G, Seehofer D, Burk O, Schwab M, and Zanger UM (2016) Genomewide comparison of the inducible transcriptomes of nuclear receptors CAR, PXR and PPAR $\alpha$ in primary human hepatocytes. Biochim Biophys Acta 1859:1218-1227.

Keisner SV and Shah SR (2011) Pazopanib: the newest tyrosine kinase inhibitor for the treatment of advanced or metastatic renal cell carcinoma. Drugs 71:443-454. Lehmann JM, McKee DD, Watson MA, Willson TM, Moore JT, and Kliewer SA (1998) The human orphan nuclear receptor PXR is activated by compounds that regulate CYP3A4 gene expression and cause drug interactions. $J$ Clin Invest 102 : 1016-1023.

Liu XJ, Lu H, Sun JX, Wang SR, Mo YS, Yang XS, and Shi BK (2016) Metabolic behavior prediction of pazopanib by cytochrome P450 (CYP) 3A4 by molecular docking. Eur J Drug Metab Pharmacokinet 41:465-468.

Maglich JM, Parks DJ, Moore LB, Collins JL, Goodwin B, Billin AN, Stoltz CA, Kliewer SA, Lambert MH, Willson TM, et al. (2003) Identification of a novel human constitutive androstane receptor (CAR) agonist and its use in the identification of CAR target genes. J Biol Chem 278:17277-17283.

Maglich JM, Stoltz CM, Goodwin B, Hawkins-Brown D, Moore JT, and Kliewer SA (2002) Nuclear pregnane $\mathrm{x}$ receptor and constitutive androstane receptor regulate overlapping but distinct sets of genes involved in xenobiotic detoxification. Mol Pharmacol 62:638-646.

Marschall HU, Wagner M, Zollner G, Fickert P, Diczfalusy U, Gumhold J, Silbert D, Fuchsbichler A, Benthin L, Grundström R, et al. (2005) Complementary stimulation of hepatobiliary transport and detoxification systems by rifampicin and ursodeoxycholic acid in humans. Gastroenterology 129:476-485.

Moscovitz JE, Lin Z, Johnson N, Tu M, Goosen TC, Weng Y, and Kalgutkar AS (2017) Induction of human cytochrome P450 3A4 by the irreversible myeloperoxidase inactivator PF-06282999 is mediated by the pregnane X receptor. Xenobiotica 1-9 DOI: $10.1124 /$ pr.55.3.4.

New Drug Application (NDA)-022465 (2009) Clinical Pharmacology and Biopharmaceutics Reviews, Center for Drug Evaluation and Research, Food and Drug Administration, Bethesda, MD

Olinga P, Elferink MG, Draaisma AL, Merema MT, Castell JV, Pérez G, and Groothuis GM (2008) Coordinated induction of drug transporters and phase I and II metabolism in human liver slices. Eur J Pharm Sci 33:380-389.

Pelkonen O, Turpeinen M, Hakkola J, Honkakoski P, Hukkanen J, and Raunio H (2008) Inhibition and induction of human cytochrome P450 enzymes: current status. Arch Toxicol 82:667-715.

Raucy JL, Mueller L, Duan K, Allen SW, Strom S, and Lasker JM (2002) Expression and induction of CYP2C P450 enzymes in primary cultures of human hepatocytes. $J$ Pharmacol Exp Ther 302:475-482.

Ruggeri RB, Buckbinder L, Bagley SW, Carpino PA, Conn EL, Dowling MS, Fernando DP, Jiao W, Kung DW, Orr ST, et al. (2015) Discovery of 2-(6-(5-Chloro-2 methoxyphenyl)-4-oxo-2-thioxo-3,4-dihydropyrimidin-1(2H)-yl)acetamide (PF-06282999): a highly selective mechanism-based myeloperoxidase inhibitor for the treatment of cardiovascular diseases. J Med Chem 58:8513-8528.

Seidegård J and Ekström G (1997) The role of human glutathione transferases and epoxide hydrolases in the metabolism of xenobiotics. Environ Health Perspect 105 (Suppl 4):791-799.

Sinz M (2015) Avoiding PXR and CAR activation and CYP3A4 enzyme induction. Top Med Chem 9:159-190.

Sinz M, Kim S, Zhu Z, Chen T, Anthony M, Dickinson K, and Rodrigues AD (2006) Evaluation of 170 xenobiotics as transactivators of human pregnane $\mathrm{X}$ receptor 
(hPXR) and correlation to known CYP3A4 drug interactions. Curr Drug Metab 7: $375-388$.

Sueyoshi T, Green WD, Vinal K, Woodrum TS, Moore R, and Negishi M (2011) Garlic extract diallyl sulfide (DAS) activates nuclear receptor CAR to induce the Sult1e1 gene in mouse liver. PLoS One 6:e21229.

Sugatani J, Kojima H, Ueda A, Kakizaki S, Yoshinari K, Gong QH, Owens IS, Negishi M, and Sueyoshi T (2001) The phenobarbital response enhancer module in the human bilirubin UDP-glucuronosyltransferase UGT1A1 gene and regulation by the nuclear receptor CAR. Hepatology 33:1232-1238.

Sugatani J, Sueyoshi T, Negishi M, and Miwa M (2005) Regulation of the human UGT1A1 gene by nuclear receptors constitutive active/androstane receptor, pregnane X receptor, and glucocorticoid receptor. Methods Enzymol 400:92-104.

Sutter TR, Tang YM, Hayes CL, Wo YY, Jabs EW, Li X, Yin H, Cody CW, and Greenlee WF (1994) Complete cDNA sequence of a human dioxin-inducible mRNA identifies a new gene subfamily of cytochrome P450 that maps to chromosome 2. J Biol Chem 269:13092-13099.

Synold TW, Dussault I, and Forman BM (2001) The orphan nuclear receptor SXR coordinately regulates drug metabolism and efflux. Nat Med 7:584-590.

Tan AR, Dowlati A, Jones SF, Infante JR, Nishioka J, Fang L, Hodge JP, Gainer SD, Arumugham T, Suttle AB, et al. (2010) Phase I study of pazopanib in combination with weekly paclitaxel in patients with advanced solid tumors. Oncologist 15: 1253-1261.

Wang YM, Ong SS, Chai SC, and Chen T (2012) Role of CAR and PXR in xenobiotic sensing and metabolism. Expert Opin Drug Metab Toxicol 8:803-817.

Wenning LA, Hanley WD, Brainard DM, Petry AS, Ghosh K, Jin B, Mangin E, Marbury TC, Berg JK, Chodakewitz JA, et al. (2009) Effect of rifampin, a potent inducer of drug-metabolizing enzymes, on the pharmacokinetics of raltegravir. Antimicrob Agents Chemother 53:2852-2856.

Wienkers LC and Heath TG (2005) Predicting in vivo drug interactions from in vitro drug discovery data. Nat Rev Drug Discov 4:825-833.
Williams JA, Hyland R, Jones BC, Smith DA, Hurst S, Goosen TC, Peterkin V, Koup JR, and Ball SE (2004) Drug-drug interactions for UDP-glucuronosyltransferase substrates: a pharmacokinetic explanation for typically observed low exposure (AUCi/AUC) ratios. Drug Metab Dispos 32:1201-1208

Willson TM and Kliewer SA (2002) PXR, CAR and drug metabolism. Nat Rev Drug Discov 1:259-266.

Xie W, Barwick JL, Downes M, Blumberg B, Simon CM, Nelson MC, NeuschwanderTetri BA, Brunt EM, Guzelian PS, and Evans RM (2000) Humanized xenobiotic response in mice expressing nuclear receptor SXR. Nature 406:435-439.

Xie W, Yeuh MF, Radominska-Pandya A, Saini SP, Negishi Y, Bottroff BS, Cabrera GY, Tukey RH, and Evans RM (2003) Control of steroid, heme, and carcinogen metabolism by nuclear pregnane $\mathrm{X}$ receptor and constitutive androstane receptor. Proc Natl Acad Sci USA 100:4150-4155.

$\mathrm{Xu}$ C, Li CY, and Kong AN (2005) Induction of phase I, II and III drug metabolism/ transport by xenobiotics. Arch Pharm Res 28:249-268.

Yajima K, Uno Y, Murayama N, Uehara S, Shimizu M, Nakamura C, Iwasaki K, Utoh M, and Yamazaki H (2014) Evaluation of 23 lots of commercially available cryopreserved hepatocytes for induction assays of human cytochromes P450. Drug Metab Dispos 42:867-871.

Yueh MF, Huang YH, Hiller A, Chen S, Nguyen N, and Tukey RH (2003) Involvement of the xenobiotic response element (XRE) in Ah receptor-mediated induction of human UDP-glucuronosyltransferase 1A1. J Biol Chem 278:15001-15006.

Address correspondence to: Jamie Moscovitz, Medicine Design, Pfizer Worldwide Research and Development, 610 Main Street, Cambridge, MA 02139. E-mail: jamie.moscovitz@pfizer.com; or Yan Weng, BioMedicine Design, Pfizer Worldwide Research and Development, 610 Main Street, Cambridge, MA 02139. E-mail: yan.weng2@pfizer.com 